\title{
Remediation potential of native plant species in Iran to remove diesel from contaminated brownfields
}

\author{
Manuscrit reçu le 21 décembre 2016 et accepté le 5 mai 2017 \\ Ali Daryabeigi ZAND* \\ Graduate Faculty of Environment, University of Tehran,
}

\begin{abstract}
Redevelopment of brownfields sites is a challenging issue throughout the world, which has gained increasing attention in recent years. Lands affected by oil wastes and products are among common types of brownfields sites in Iran. Sorghum (Sorghum bicolor) was employed to remediate diesel polluted soils in this study. The main aims of this study were to examine the phytoremediation potential of Sorghum (Sorghum bicolor) to remove hydrocarbons from spiked soils as well as the influence of diesel on growth characteristics of the sorghum. Soils were artificially contaminated with 100, 500, 1000, 3000 and $5000 \mathrm{mg} / \mathrm{kg}$ diesel. Residual hydrocarbons were measured at different intervals. Establishment of considerable biomass is one critical factor affects phytoremediation potential of plant species which has been addressed in this research. Sorghum demonstrated promising growth behaviour in contaminated soils; however, higher concentrations of hydrocarbons depressed growth parameters of sorghum to some extent. The highest hydrocarbon removal rate was obtained in presence of $100 \mathrm{mg} / \mathrm{kg}$ diesel, which was $93.54 \%$ compared to the initial level. Results showed that sorghum is an effective plant that can be used in remediation of hydrocarbon contaminated sites.
\end{abstract}

Keywords: Brownfields, Diesel, Phytoremediation, Soil, Sorghum.

\section{INTRODUCTION}

Redevelopment of brownfields sites is a challenging issue throughout the world, which has gained increasing attention in recent years. Brownfields can be defined in different ways in different nations. For instance, the US EPA defines brownfields as a property, the expansion, redevelopment, or reuse of which may be complicated by the

\footnotetext{
Corresponding Author: 23 Ghods Street, Enghelab Ave., Graduate Faculty of Environment, University of Tehran, P.O. Box 14155-6135, Tehran, Iran. Tel.: +989123107933. E-mail: adzand@ut.ac.ir
} 
presence or potential presence of a hazardous substance, pollutant, or contaminant (Lin, 2013; Elrahman, 2016). The number of brownfields is estimated to be more than half a million in the U.S, while in some countries including Iran number and situation of brownfields has not been identified to date. Cleaning up these sites can promote job growth, local tax bases enhancement, takes development pressures off of undeveloped lands and greenfields, protect human health and the environment and improve quality of life (De Sousa, 2003; Li et al., 2016).

The importance of brownfields redevelopment is increasing, particularly in urban areas not only because of the environmental concerns but also due to the scarcity of land in densly-populated areas for various purposes such as residential, commercial, industrial, commercial use and etc. Redevelopment of brownfields sites in many courtiers has frequently reported in recent decade (De Sousa, 2003; Li et al., 2016). However, there are many barriers that complicate redevelopment of brownfields sites in both developed and developing countries such as selection of effective cleaning methods and costs associated with remediation technologies. Other obstacles includes, but not limited to contamination level, liability issues, future land use, capital investments, operation and maintenance issues and lack of enough number of experts in field of brownfields redevelopment in governmental agencies (Elrahman, 2016).

Contaminated sites around oil refineries affected by oil wastes and products in different ways are among common brownfields in Iran in which uncontrolled disposal of oil-related wastes has polluted soil resources over the past decades. Many of these sites which are now inside the cities borders have become abandoned for many years. Redevelopment and remediation of these sites has almost been relinquished mainly due to economical and technical barriers. High cost associated with conventional remediation technologies is a principal obstacle to redevelopment of brownfields in many developing courtiers including Iran.

Using plants and their associated microorganisms which is mainly known as phytoremediation or plan-aid remediation is an emerging green technology that can be a promising solution to restore various brownfiels including hydrocarboncontaminated sites. Phytoremediation of petroleum hydrocarbon-polluted soils most likely works by a process called rhizosphere degradation or rhizoremediation, in which microbial activity in proximity to plant roots is stimulated by root exudates (Kulakow et al., 2000). Degradation of organic contaminants such as hydrocarbons in the rhizosphere of various plant species has been reported in the literature (Abhilash et al., 2009; Liu et al., 2014; Bisht et al., 2015). The impact of the maize on fuel oil degradation was evaluated in a laboratory study by Chaineau et al., (2000), where the maize seeds were grown in beakers with soil and fuel oil (initial concentration of hydrocarbons was $3300 \mathrm{mg} / \mathrm{kg}$ ). Their results indicated that in the presence of plants, the removal of hydrocarbons was 20 percent faster than in the non-vegetated soils. Many studies have shown hydrocarbons degradation can occur through phytoremediation successfully (Escalante-Espinosa et al., 2005; Huang et al., 2005; Merkl et al., 2005). However, a few experiments suggest that degradation of hydrocarbons is not considerably increased by the rhizosphere effect (Kulakow et al., 
2000). Rhizosphere impact on hydrocarbon breakdown may vary from one plant to another plant.

The most important industry in Iran, i.e. oil industry generates huge amount of oil wastes annually which are mainly dumped or landfilled without enough environmental care. Pipeline fracture and leakage from gas stations are also responsible for intrusion of hydrocarbons to soil. Concentration of hydrocarbons in soil is one critical factor affecting plant establishment in contaminated sites and, therefore, phytoremediation potential of plant species in sites in need of clean up. The main aims of this research were to investigate the influence of different levels of fresh diesel in soil on germination and growth parameters of sorghum (Sorghum bicolor) which is a native plant species in Iran as well as its phytoremediation potential.

\section{MATERIALS AND METHODS}

Bulk sample of uncontaminated soil was collected from lands around the Oil Refinery of Tehran. Air dried soil passed through a 4-mm sieve and mixed thoroughly. Some physico-chemical properties of the used soil are presented in Table 1.

Table 1: Physicochemical properties of the uncontaminated soil

\begin{tabular}{lll}
\hline Parameter & Value & Analytical method \\
\hline \hline Clay $(\%)$ & 30 & Hydrometer measurement \\
Organic matter $(\%)$ & 0.9 & Walkley-Black \\
Soil pH & 7.4 & $1: 1$ soil/water slurry \\
Electrical Conductivity $(\mathrm{dS} / \mathrm{m})$ & 3.23 & $1: 2$ soil/water slurry \\
Total N $(\%)$ & 0.1 & Kjeldahl \\
Phosphorus $(\mathrm{mg} / \mathrm{kg})$ & 26.2 & Olsen \\
\hline
\end{tabular}

There was no background contamination in the soil. Clean soil was artificially spiked by commercial diesel to gain $100,500,1000,3000$, and $5000 \mathrm{mg} / \mathrm{kg}$ contamination levels in soil. Samples were landfarmed and mixed using a garden hoe to achieve homogenous distribution of spiked hydrocarbons in soil before placement in pots. Polyvinyl chloride (PVC) pots were filled with 800 grams of the contaminated soil as well as uncontaminated control soil, in triplicate. Sorghum (Sorghum bicolor) was cultivated over a 60-day period in greenhouse under sunlight. Monitoring of plant growth was carried out every 20 day; however, germination rate was monitored everyday over the first 15 days of the trial to reach the highest possible rate. Number of seeds germinated in different treatments was counted and expressed as a percentage of the initial number of planted seeds. Shoot biomass and root biomass were also determined every 20 days. Biomass and length of aboveground parts (shoot) and underground parts (root) were also monitored by considering destructive pots. Harvested plants were carefully rinsed with deionized water and oven-dried in $70{ }^{\circ} \mathrm{C}$ for 48 hours, then weighed. 
In order to measure hydrocarbons concentrations in soil samples, they were initially air dried at room temperature and passed through a $2 \mathrm{~mm}$ sieve. Ultrasonic extraction was performed using dichloromethane solvent. Ten millilitres of dichloromethane was added to about 5 grams of contaminated soil and then it was placed in an ultrasonic water bath for three minutes at room temperature. All of these operations were repeated three times (US EPA, 1998). Two $\mu$ l of the concentrated extract was injected into a gas chromatograph equipped with a flame ionization detector (FID) in order to determine residual hydrocarbon concentration in soil samples. Results were analyzed by one-way using the Statistical Package for Social Sciences (SPSS) 20.0 for Windows, SPSS Inc., IL, USA.

\section{RESULTS AND DISCUSSION}

Sorghum demonstrated considerable germination and growth rates in presence of different levels of commercial diesel. However, higher levels of hydrocarbons i.e. 3000 and $5000 \mathrm{mg} / \mathrm{kg}$ diesel reduced plant growth to some extent. Final germination of plants after 15 days is shown in Fig. 1. Germination rate didn't show any variation after two weeks.

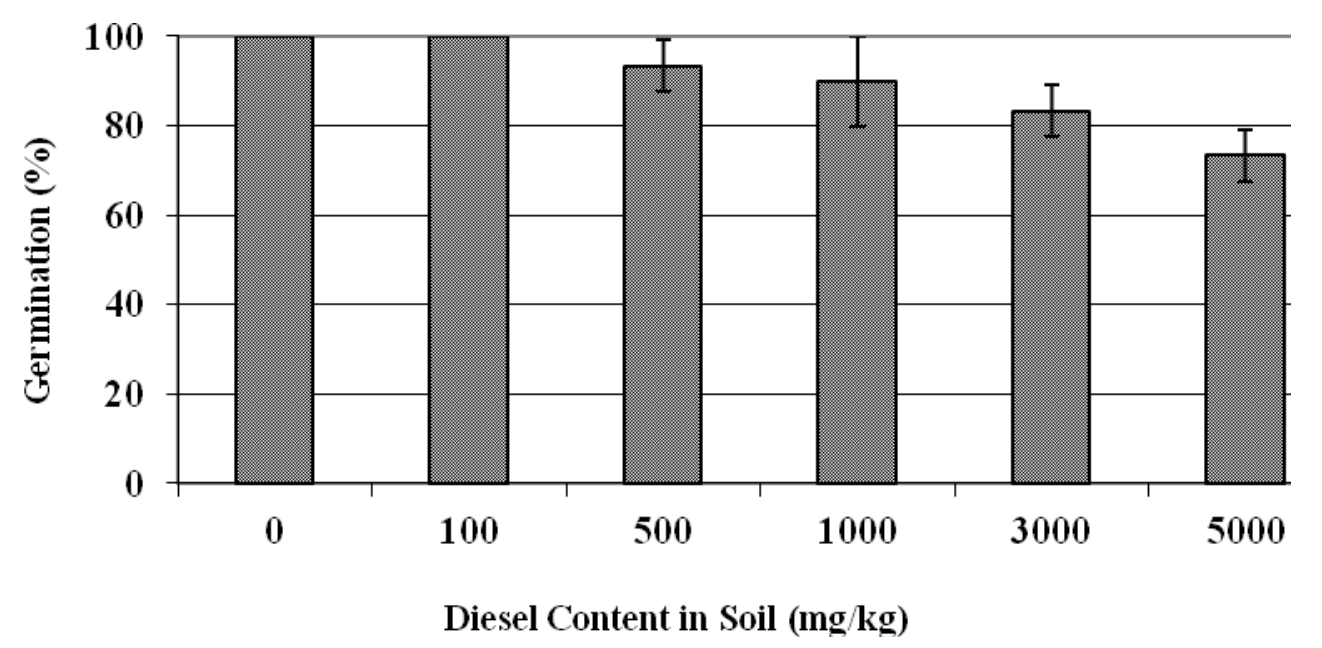

Fig. 1: Final germination of sorghum in diesel-contaminated soils.

Sensitivity of germination as well as initial growth steps of plant species can influence the phytoremediation efficiency (Potashev et al., 2014). Relation between poor germination and subsequent poor plant growth in hydrocarbon contaminated soil has been reported in the literature (Chaineau et al., 1997). Petroleum hydrocarbon pollution did not have significant influence on germination rate of sorghum in soils contaminated with 100,500 , and $1000 \mathrm{mg} / \mathrm{kg}$ diesel; however, the subsequent growth was reduced to some extent in presence of $1000 \mathrm{mg} / \mathrm{kg}$ diesel in soil. Seedling emergence of sorghum reduced by $26.7 \%$ in the soil spiked with $5000 \mathrm{mg} / \mathrm{kg}$. Seedling emergence, which is more sensitive to freshly added hydrocarbons compared 
to aged contamination, can be inhibited or delayed by toxic effects of hydrocarbons. Salanitro et al., (1997) reported seedling emergence reduction of corn, wheat, and oat in soil contaminated with heavy crude oil. Some hydrocarbons can enter into the plant seeds and disturb metabolic reactions or even kill the embryo and inhibit germination, as suggested by Adam and Duncan (2002).

Plant growth parameters in different treatments are presented in Table 2.

Table 2: Growth parameters of sorghum for destructive pots

\begin{tabular}{cccccccc}
\hline \multirow{2}{*}{ Parameter } & \multirow{6}{*}{ Time (Day) } & \multicolumn{6}{c}{ Initial content of diesel in soil (mg/kg) } \\
\cline { 3 - 8 } & & $\mathbf{0}$ & $\mathbf{1 0 0}$ & $\mathbf{5 0 0}$ & $\mathbf{1 0 0 0}$ & $\mathbf{3 0 0 0}$ & $\mathbf{5 0 0 0}$ \\
\hline \multirow{3}{*}{ Root biomass (cm) } & 20 & 3.0 & 3.0 & 2.8 & 2.5 & 1.9 & 1.7 \\
& 40 & 6.6 & 6.4 & 6.2 & 5.7 & 4.7 & 4.0 \\
& 60 & 10.2 & 10.0 & 9.3 & 8.1 & 6.8 & 6.1 \\
\hline \multirow{3}{*}{ Shoot biomass (gr) } & 20 & 2.9 & 2.7 & 2.6 & 2.3 & 1.9 & 1.6 \\
& 40 & 6.4 & 6.0 & 5.7 & 5.2 & 4.4 & 3.8 \\
& 60 & 10.0 & 9.2 & 8.6 & 7.8 & 7.1 & 6.1 \\
\hline \multirow{3}{*}{ Root Lenght (cm) } & 20 & 18.0 & 16.0 & 16.0 & 13.5 & 11.8 & 9.5 \\
& 40 & 33.0 & 34.0 & 31.0 & 26.0 & 21.4 & 18.8 \\
& 60 & 46.0 & 43.0 & 41.0 & 38.0 & 32.0 & 24.5 \\
\hline
\end{tabular}

Shoot height of the sorghum was also measured over the course of the experiment. Shoot height reduction in all contaminated treatments were less than 50\% compared to control treatment, but reduction in shoot height was considerable in presence of $5000 \mathrm{mg} / \mathrm{kg}$ diesel in soil, i.e. $41.7 \%$ at the end of the experiment. Reduction in shoot biomass as well as root biomass of sorghum in presence of 100 and $500 \mathrm{mg} / \mathrm{kg}$ diesel in soil was almost negligible. In other word, addition of up to $500 \mathrm{mg} / \mathrm{kg}$ fresh diesel to soil didn't affect biomass production of sorghum. Biomass production of sorghum decreased with increasing concentrations of diesel in soil. For instance, addition of $5000 \mathrm{mg} / \mathrm{kg}$ diesel to soil reduced dried weights of sorghum root and shoot by $40.2 \%$ and $39 \%$, respectively, after 60 days, compared to control treatment. Both root biomass and shoot biomass was greatest for the control treatment in which uncontaminated soil was used as expected. Results indicated that sensitivity of shoot biomass is almost comparable with that of root biomass. Both are tolerant to lower levels of diesel in soil, while they are more sensitive to higher diesel content in soil. After 40 days, root and shoot growth of sorghum showed a decreasing trend. It may be attributed to both inhibition effects of diesel and nutrient depletion in soil, due to lack of nutrient supplement during the experiment. Plant growth rate was also diminished in uncontaminated control soil after 40 days to some extent. Nutrient addition to soil may promote sorghum growth in later stages of phytoremediation experiment. In general, results indicated that sorghum is definitely tolerant to different levels of hydrocarbons in soil up to $1000 \mathrm{mg} / \mathrm{kg}$, while higher levels of hydrocarbons 
could reduce sorghum growth parameters considerably. Plant growth reduction in presence of hydrocarbons in soil has been reported in the literature. Chaineau et al., (1997) reported a growth rate reduction of two plant species by more than 80 percent. Gallego-Martinez et al., (2000) also found a reduction of biomass for three plant species supporting the obtained results in this study. Inhibition of growth might be rooted in toxic effects of freshly added hydrocarbons to soil. Diesel usually has more severe effects on plant growth compared to other petroleum hydrocarbon products e.g. heavy crude oil at the comparable levels. Small molecules of hydrocarbons are able to enter and pass through cell membranes leading to reduced membrane integrity or finally death of the cell (Merkl et al., 2004). It may be worth mentioning that initial landfarming and mixing of the spiked soils could lower the effects of low-molecular weight components of diesel in this study compared to researches conducted with real non-spiked soils contaminated with fresh diesel. Shoot biomass establishment is one critical factor controlling phytoremediation potential of a given plant species, but it should be noticed that greater shoot biomass measurements are not necessarily indicator of enhanced remediation (Banks et al., 2003). On-site observations showed that sorghum posses extensive and dense root system. Phytoremediation potential of sorghum in different treatments is shown in Fig. 2. It can be seen in Fig. 2 that hydrocarbon concentrations decreased in all treatments including non-vegetated control treatment. Remarkable impact of sorghum on diesel removal at different sampling intervals was obtained. Natural attenuation could reduce hydrocarbon level in soil contaminated with 100,500 , and $1000 \mathrm{mg} / \mathrm{kg}$ by $30.61 \%, 30.01 \%$, and 28.39 $\%$, respectively, at the end of the experiment. Natural attenuation efficiency dropped slightly with increasing concentrations of diesel in soil. Petroleum hydrocarbons were naturally mitigated by only $28.46 \%$ in presence of $5000 \mathrm{mg} / \mathrm{kg}$ diesel in unplanted control soil. Natural attenuation of diesel is generally caused by volatilization of lowmolecular weight compounds, especially at the beginning of the experiment, as well as soil microbial activity. Sorghum caused a considerably greater hydrocarbon removal compared to unplanted soil in which hydrocarbons were attenuated naturally. Plant-aid remediation of organic pollutants such as hydrocarbons benefit from the synergy between soil bacteria and plant roots that leads to increase in rate of degradation of persistent and toxic compounds. Positive effects have thus been cited for a wide range of molecules ranging from BTEX (benzene, toluene, ethylbenzene, and xylenes) and simple aliphatics in light crude oil and fuel (Abhilash et al., 2009) to more complex and highly persistent contaminants such as high molecular weight polycyclic aromatic hydrocarbons (Johnson et al., 2005; Liu et al., 2014; Xiao et al., 2015), pesticides, and explosives (Van Aken, 2009). The highest removal in presence of different levels of hydrocarbons in soil was obtained at the end of the experiment for all treatments. Sorghum finally reduced diesel content of soil by 93.54\%, $92.2 \%$, and $91.18 \%$, respectively, in soils contaminated with 100,500 , and $1000 \mathrm{mg} / \mathrm{kg}$ compared to the initial concentrations. 

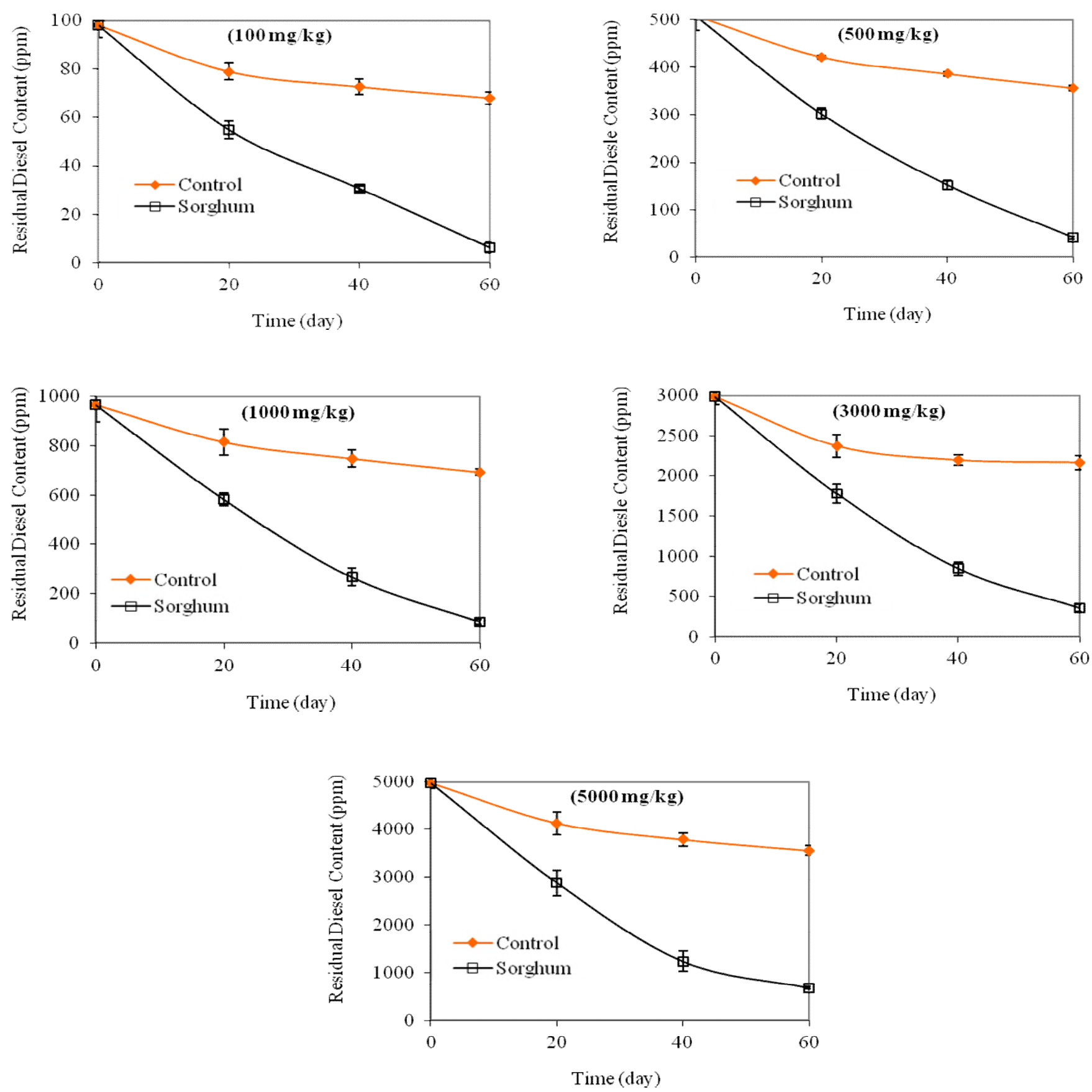

Fig. 2: Residual amounts of hydrocarbons in soil during the experiment under various scenarios.

Phytoremediation effectiveness decreased slightly at higher concentrations of diesel i.e. 3000 and $5000 \mathrm{mg} / \mathrm{kg}$. Phytoremediation potential of sorghum in presence of 3000 and $5000 \mathrm{mg} / \mathrm{kg}$ hydrocarbons in soil decreased to $88.18 \%$ and $86.35 \%$, respectively. In other words, for all contents of hydrocarbons the phytoremediation potential was not dropped below 86\%. Reduction in phytoremediation potential at higher concentrations may be attributed to both the toxic effects of hydrocarbons in higher 
contents and their influence on plant and associated microbial biomass production. Stimulation of soil microorganisms is the principal mechanism by which hydrocarbons are degraded and removed. The remediation process in which hydrocarbons are transformed by microorganisms in the rhizosphere zone (i.e., the microbe-rich zone in close contact with the root system of a given plant) is referred to rhizodegradation or phytostimulation (Cebron et al., 2010; Bisht et al., 2015). Thus it can be assumed that higher root biomass, as obtained for lower hydrocarbon contents, means a larger rhizosphere for microbial population and it is correlated with a higher degradation of hydrocarbons in soil (Merkl et al., 2005).

Fig. 2 reveals decrease in hydrocarbon removal rate after 40 days in all panted treatments that may be caused by plant growth reduction. Another possible reason is a probable change in composition and amount of root exudates at later stages of sorghum growth (Chen et al., 2016). Merkl et al., (2005) suggested that degrading microorganisms are stimulated in their growth and activity by root exudates that vary with plant age and nutritional status. Quantitative and qualitative change in of plant exudates with plant age can affect population and activity of hydrocarbon degrading microorganisms in the rhizosphere, therefore, affect phytoremediation efficiency of a given plant species. Non-appreciable TPHs removal was also observed in a phytoremediation study by Escalante-Espinosa et al., (2005) from 120 to 180 days of culture in planted and unplanted treatments. Hutchinson et al., (2001) and EscalanteEspinosa et al., (2005) observed the highest phytoremediation rate at the first stage of culture in their experiment (up to 60 days), which is almost comparable with the obtained results in the current research.

\section{CONCLUSIONS}

Results demonstrated that sorghum is a promising plant for phytoremediation of diesel contaminated soils, especially for low to moderate contamination levels. Relatively high reduction of hydrocarbons in presence of sorghum may be attributed to its suitable tolerance and growth in contaminated soil used in the current research. However, sorghum growth and phytoremediation potential were reduced to some extent in presence of 3000 and $5000 \mathrm{mg} / \mathrm{kg}$ diesel in soil. Sorghum showed best shoot and root biomass production in contaminated soil with $100 \mathrm{mg} / \mathrm{kg}$ that also caused highest hydrocarbon dissipation compared to unplanted soil suggests that greater root and shoot biomass is likely to be associated with higher microbial population and activity in the rhizosphere zone and, hence higher remediation performance. Sorghum is well-known and easy to access plant species in Iran and many other countries. Obtained results indicated that soil remediation with these plant species can be a promising approach to manage diesel contaminated brownfields. It is suggested to investigate the influence of higher contents of diesel in soil on sorghum growth parameters and its clean up performance in future studies. Conducting field trials can also yield more insight into the real-world performance of sorghum under various scenarios. 
Bulletin de la Société Royale des Sciences de Liège, Vol. 86, articles, 2017, p. 57 - 66

\section{Acknowledgement}

The research project was funded by Dorineh Siah Knowledge-Based Company, under contract No. D/100306. The author also thanks the University of Tehran for support.

\section{REFERENCES}

Abhilash, P.C., Jamil, S., Singh, N., (2009). Transgenic plants for enhanced biodegradation and phytoremediation of organic xenobiotics. Biotechnol. Adv., 7: 474-488.

Adam, G., Duncan, H.J., (2002). Influence of diesel fuel on seed germination. Environ. Pollut., 120: 363-370.

Banks, M.K., Schwab, P., Liu, B., (2003). Effect of plants on the degradation and toxicity of petroleum contaminants in soil: A field assessment. Adv. Biochem. Eng. Biotech., 78: 75-96.

Bisht, S., Pandey, P., Bhargava, B., Sharma, S., Kumar, V., Sharma, K.D. (2015). Bioremediation of polyaromatic hydrocarbons (PAHs) using rhizosphere technology. Braz. J. Microbiol., 46 (1): 7-21.

Cebron, A., Louvel, B., Faure, P., France-Lanord, C., Chen, Y., Murrell, J.C. (2010). Root exudates modify bacterial diversity of phenanthrene degraders in PAHpolluted soil but not phenanthrene degradation rates. Environ. Microbiol., 13: $722-736$.

Chaineau, C.H., Morel, J.L., Oudot, J. (2000). Biodegradation of fuel oil hydrocarbons in the rhizosphere of maize. J. Environ. Qual., 29 : 569-578.

Chaineau, C.H., Morel, J.L., Oudot, J., (1997). Phytotoxicity and plant uptake of fuel oil hydrocarbons. J. Environ. Qual., 26: 1478-1483.

Chen, Z.J., Tian, Y.H., Zhang, Y., Song, B.R., Li, H.C., Chen, Z.H., (2016). Effects of root organic exudates on rhizosphere microbes and nutrient removal in the constructed wetlands. Ecol. Eng., 92: 243-250.

De Sousa, C. A., (2003). Turning brownfields into green space in the City of Toronto. Landscape Urban Plan., 62 (4): 181-198.

Elrahman, A.S.A., (2016). Redevelopment aspects for brownfields sites in Egypt. P. Environ. Sci., 34: 25-35.

Escalante-Espinosa, M.E., Gallegos-Martınez, E., Favela, T., Gutierrez-Rojas, M., (2005). Improvement of the hydrocarbon phytoremediation rate by Cyperus laxus Lam. inoculated with a microbial consortium in a model system. Chemosphere, 59: 405-413.

Gallegos-Martinez, M.G., Gomez-Trujillo, A.G., Gonzales, L.G., (2000). Diagnostic and resulting approached to restore petroleum-contaminated soil in a Mexican tropical swamp. Water Sci. Technol., 42: 377-384.

Huang, X.D., El-Alawi, Y., Gurska, J., Glick, B., Greenberg, B., (2005). A multiprocess phytoremediation system for decontamination of persistent total petroleum hydrocarbons (TPHs) from soils. Microchem. J., 81: 139-147. 
Hutchinson, S.L., Banks, M.K., Schwab, A.P., (2001). Phytoremediation of aged petroleum sludge: Effect of inorganic fertilizer. J. Environ. Qual., 30: 395403.

Johnson, D.L., Anderson, D.R., McGrath, S.P., (2005). Soil microbial response during the phytoremediation of a PAH contaminated soil. Soil Biol. Biochem., 37 (12): 2334-2336.

Kulakow, P.A., Schwab, A.P., Banks, M.K., (2000). Screening plant species for growth on weathered, petroleum hydrocarbon-contaminated sediments. Int. J. Phytorem., 2: 297-317.

Li, X., Yang, H., Li, W., Che, Z., (2016). Public-private partnership in residential brownfield redevelopment: case studies of Pittsburgh. P. Eng., 145: 15341540 .

Lin, J., (2013). The effect of voluntary brownfields programs on nearby property values: Evidence from Illinois. J. Urban Econ., 78: 1-18.

Liu, H., Meng, F., Tong, Y., Chi, J., (2014). Effect of plant density on phytoremediation of polycyclic aromatic hydrocarbons contaminated sediments with Vallisneria spiralis. Ecol. Eng., 73: 380-385.

Merkl, N., Schultze-Kraft, R., Infante, C., (2004). Phytoremediation in the tropics-the effect of crude oil on the growth of tropical plants. Biorem. J. 8: 177-184.

Merkl, N., Schultze-Kraft, R., Infante, C., (2005). Assessment of tropical grasses and legumes for phytoremediation of petroleum-contaminated soils. Water Air Soil Pollut., 165: 195-209.

Potashev, K., Sharonova, N., Breus, I., (2014). The use of cluster analysis for plant grouping by their tolerance to soil contamination with hydrocarbons at the germination stage. Sci. Total Environ., 485-486: 71-82.

Salanitro, J.P., Dorn, P.B., Huesemann, M.H., (1997). Crude oil hydrocarbon bioremediation and soil ecotoxicity assessment. Environ. Sci. Technol., 31: 1769-1776.

US EPA., (1998). SW-846 on-line test methods for evaluating solid wastes, physical/chemical method. . US Environmental Protection Agency, Washington, DC.

Van Aken, B., (2009). Transgenic plants for enhanced phytoremediation of toxic explosives. Curr. Opin. Biotechnol., 20 (2): 231-236.

Xiao, N., Liu, R., Jin, C., Dai, Y., (2015). Efficiency of five ornamental plant species in the phytoremediation of polycyclic aromatic hydrocarbon (PAH)contaminated soil. Ecol. Eng., 75: 384-391. 